\title{
COMPUTERS AND INTUITION
}

\author{
H. Jaap van den Herik ${ }^{1}$ \\ Leiden, the Netherlands
}

\begin{abstract}
In this article ${ }^{2}$ I want to focus on the Ph.D. students who inspired Eric Postma and myself to pay attention to the topic of computers and intuition. During our time at Maastricht University five Ph.D. students (Rens Kortman, Michel van Dartel, Joyca Lacroix, Niek Bergboer, and Fred Hamburg) paved the way to formulate a basis for fertile ideas on intuition in relation to programs. In the period from January 1, 2008 to January 1, 2016 four Ph.D. students (Guido de Croon, Laurens van der Maaten, Igor Bereznoy, and Ruud Mattheij) positioned us by their research results on the right track. The conclusion is provisional, but undeniable in my opinion: mental intuition is programmable.
\end{abstract}

\section{The Run-up}

In 1978 I was able to turn my hobby into my profession. I embarked upon an ambitious Ph.D. project which would take nearly five years. It was entitled Computer Chess, the World of Chess, and Artificial Intelligence. I had many mentors, three of them would eventually become my supervisors, namely Professor H.J.M. Lombaers, Professor A.D. de Groot and Professor S.J. Doorman. Lombaers knew at that time, everything about computers, De Groot about the thinking of a chess player, and Doorman about analytic philosophy.

The first meeting on the research project with De Groot had traits of the puppy and the old master (by the way, we were chess friends and opponents in several rapid chess tournaments). "Professor, I am considering implementing your theories about the thinking of the chess player (De Groot, 1946) in a computer program and much more. Over time, this research will lead to a program that will play stronger than the human world champion.” The answer was very provocative for me: "I am glad you intend to study the work by Euwe and myself (Euwe, 1963) and I will be pleased to supervise you. Incidentally, your prediction is flawed."

"The reasoning is as follows:

[Assumption] (1) Intuition is a vital part of chess,

[Assumption] (2) Grandmasters play so well because they have intuition at their disposal, and

[Proposition] (3) Intuition cannot be programmed, hence

[Conclusion] (4) Computers will never play at grandmaster level."

There I was sitting, opposite my future supervisor, a scholar of international renown. "Excuse me, Professor, that I take the liberty to contradict you. Indeed, I do not know exactly how it will take place, but I believe that new technologies will find a solution to the problem you posed."

\section{The Ph.D. defence}

On June 21, 1983 my Ph.D. defence took place. First, there was opposition by a colleague from the audience (about a mathematical proposition). Then Professors Herschberg, Van der Poel, Gierveld, Sciarone, and Doorman fulfilled their role as opponents. After 45 minutes the Beadle came in. It was her first Ph.D. defence

\footnotetext{
1 Leiden University, Leiden Centre of Data Science, P.O. Box 9512, 2300 RA Leiden, the Netherlands. Email: jaapvandenherik@gmail.com.

${ }^{2}$ The article is an abridged and slightly adapted version of my valedictory address (titled: Intuition is Programmable) from Tilburg University to be held on January 29, 2016). The original version is available at https://www.universiteitleiden.nl/binaries/content/assets/science/lcds/20160202_oratie_vdn_herik_web_uk.pdf (English version), and at https://www.universiteitleiden.nl/binaries/content/assets/science/lcds/20160202_oratie_web_vdn_herik_nl.pdf (Dutch version).
} 
as Beadle. She waved the wand before letting it go down on the floor. Rector Sikkema gestured "No, No, Not on the floor" and spoke the unprecedented words: "I extend the Ph.D. defence by 10 minutes to give Professor De Groot, who has come all the way from Schiermonnikoog, the opportunity to participate in the opposition."

So we renewed our discussion, this time publicly: intuition, intuition and intuition again. Without intuition there could be no strong chess program. It sounded like an obiter dictum. Fortunately, I was well prepared and I held my positions. The audience held its breath, they saw a real clash of opinions. After the deliberation the first supervisor, Professor Lombaers, was assigned the task of awarding me the Ph.D. title and to speak the laudatio. He took no less than three quarters of an hour and outlined eloquently my research, the promotion and the future.

\section{$3 \quad$ Intermediary}

In our 10-minute dialogue Professor De Groot and I showed the public that we were evenly matched, that the discussion was interesting and that we were both convinced that we were right. De Groot, however, felt that he wrongly had not received his right from his promovendus. Six days after the promotion, I received a draft article entitled "About Chess Intuition or computers as world champion, the blind spot of Van den Herik" that he submitted for publication in the weekly magazine Intermediair (De Groot, 1983). I was invited to write a short epilogue. Of course, I did so with glowing contradiction. You will, however, be surprised: my esteem for Professor De Groot rose to great heights. "What a fighter, what a chess player, what a scientist."

In 1987, Professor Marcel Fresco was our intermediary. He organised a Studium Generale in Leiden in the context of Artificial Intelligence. The two rivals were Adriaan de Groot and Jaap van den Herik. I had just been appointed professor in Maastricht, and Adriaan extended his heartfelt congratulations to me. Then the show began. I had my 10-minute presentation carefully prepared with slides and showed the latest impressive performances achieved by CHIPTEST (predecessor of DEEP THOUGHT, later named DEEP BLUE by IBM). Then it was Adriaan's turn to present his ideas. He emphasised the role of intuition and mitigated the performances by CHIPTEST. Subsequently the audience had to vote. According to Marcel Fresco the result was 50-50. I do not remember which of us felt wronged. Probably both. Immediately thereafter, the pièce de résistance followed: an hour-long debate with the public and each other on the future playing strength of machines. Afterwards, we both believed that we were able to convincingly present our arguments. After a brief break to give the audience time to reflect on what they heard, Marcel Fresco asked for a final vote. From my vantage point, I could see people in the front row voting for me instead of against, as was the case for the initial vote. The messy conduct of the voting made the outcome uncertain.

As an experienced intermediary Marcel Fresco announced the final result: it was 50-50 again. If I reflect on this moment many years later, then I believe Marcel was being kind to me. Yes, I had won some votes, but also lost some (how was that possible?). The pros and cons among the voters were completely rearranged. By recalling the audience in my mind, my estimate would be a small advantage to Adriaan. I comfort myself with the thought that at that time they did not know in Leiden the power of the looming technology, of big trees, and, of today's Big Data.

\section{The Breakthrough}

On May 11, 1997 the major (and, in my opinion expected) breakthrough took place. DEEP BLUE defeated world champion Garry Kasparov by a score of 3.5 points to 2.5. De Groot (1997) wrote an article in the daily newspaper NRC Handelsblad. The article was resigned, cool and aloof. The passionate fire, the one that burned brightly in the Fresco event was extinguished, even though this was the moment to reconsider his own position. After all, the fact that the human world champion was beaten by a computer program led to two possible paths.

Path 1 (Continuation of Assumption 1)

Intuition is not an essential (vital) part of chess, because a computer program without intuition was able to defeat the world champion.

Path 2 (Continuation of Assertion 3)

Intuition is a form of knowledge that we are not able to interpret correctly. Intuition is implicit in the chess knowledge that was incorporated into the program. 
Since May 11, 1997 computers play stronger chess than the human world champion. The program JONNY, winner of the World Computer Chess Championships in Leiden in July 2015, is playing an estimated 400 Elo points stronger than World Champion Magnus Carlsen.

The important lesson from my interactions with Professor De Groot is as follows. Have confidence in your supervisor, even if you totally disagree with him. In 2006 Adriaan spoke similar words when my wife Letty and I paid a last visit to him on Schiermonnikoog: "We seldom agreed, we had a lovely time. That is only possible in the world of chess and in the world of science."

5

\section{Delft-Maastricht-Tilburg-Leiden}

Over the years of my career I have been privileged to cooperate with many outstanding scholars and researchers. I am grateful to all of them. The emphasis on these cooperations is meant to be read as expressions of recognition and thanks to friends. In my valedictory address from Tilburg University all ideas collected in the period 1974-2016 came nicely together. They gave me the opportunity to picture the development of 42 years.

In 1983, after my Ph.D. defence, the ICCA Journal was born as a successor of Ben Mittman's ICCA Newsletter (Vol. 1 to Vol. 6, No. 2). So, I started in Delft as Editor-in-Chief, and subsequently took the Journal with me to Maastricht (1987-2008), Tilburg (2008-2014), and Leiden (2014-2016). The work as full professor enabled me to stimulate my environment (colleagues, students, and staff members) to give proper attention to computer chess, computer Go, computer games and their intricacies. Below some highpoints of the conceptual development with respect to intuition are described.

\section{The Implementation}

In my opinion, the core of research in general lies in guiding talented Ph.D. students. When they are performing well, then the entire institute will run well. Therefore, my attention goes out to the Ph.D. students.

All Ph.D. students are entitled to receive much attention, good guidance, exceptional treatment, access to advanced computers, and support from an excellent organisation. The secret of a successful institute is community building, open communication, acting without hidden agendas, avoiding the use of tricks, and putting Ph.D. students always first. It sounds easy, but I assure you that it is difficult to instill this culture. The idea must be internalised.

A step towards community building is organising an annual Ph.D. students day (the idea comes from colleague Henk Sol, then Delft University of Technology). Each student gives a presentation on their research, and everyone comments and assesses each other's work. Afterwards, the best presenter of the day is announced as such. It is a highly regarded distinction: the best among equals.

In my university office, a visitor once looked at the row of Ph.D. theses that I had supervised so far. He said, "Have you read them all?" My answer was succinct: "Yes, every dissertation at least ten times." So it goes in science. With each reading you see something else, you have a different perspective. For Ph.D. students I sometimes go too fast, but that is because of the way they stimulate me.

\section{Social Signal Processing}

After today (29 January, 2016), I am no longer officially connected to the same university as my long-time companion Eric Postma. He was my fifth Ph.D. student, but the first one who turned my attention to the power and promises of Signal Processing (SP), later developed into Social Signal Processing (SSP). When an Assistant Professor at the Delft University of Technology, I had learned many things in the field of medical applications through my collaboration with Eric Backer and Hans Reiber (then EUR).

\subsection{Signal Processing}

The title of Postma's (1994) thesis was SCAN: A Neural Model of Covert Attention. The thesis was about pattern recognition in ordinary images and man-made images. The research was dealing with, amongst other things, recognising images in a painting. The whole study was well-motivated, well-founded, and of high quality. Yet, I wished as a coach after this investigation to guide Eric into a new direction. Therefore, I 
suggested: "What matters is not that you recognise the image, but that you recognise the authors of the image." Eric was immediately enthusiastic: a new field of research was born. We decided to work on it in close cooperation after September 22, 1994 (his Ph.D. defence). Together we then began our scientific expedition in pattern recognition (with applications in the fields of painting) and pattern filtering from social cues. We have been supported all these years by Joke Hellemons who knew more about art than we did.

\subsection{From SP to SSP}

The idea of interpreting natural images or images appearing in a painting was an appealing subject for students in Maastricht. Over the years Postma and I together supervised some ten master students in this area and four doctoral students. From the four Ph.D. topics it can be seen that we have increasingly moved towards the understanding of images and considered the recognition of the images as a support tool for better understanding.

Our learning curve as supervisors was as follows: The Resolution of Visually Guided Behaviour (Rens Kortman, 2003), Situated Representation (Michel van Dartel, 2005), NiM: A Situated Computational Memory Model (Joyca Lacroix, 2007) ${ }^{3}$, Class and Object Detection in Natural Images (Niek Bergboer, 2007).

On our way to Social Signal Processing, Postma and I supervised a very special Ph.D. project together with Heleen Dupuis that was performed at Leiden University. It was about identifying and attributing characteristics that were related to the behaviour and the physical condition of people, to arrive at recommendations to physicians when asked to make euthanasia decisions. The title was A Computer Model for Supporting Euthanasia Decisions (Fred Hamburg, 2005). At the symposium which was organised in connection with the Ph.D. defence, the former leader of the Christian Union André Rouvoet gave a presentation on scientific progress in relation to government policy and thereafter Bishop (now Cardinal) Wim Eijk on scientific progress in relation to our belief in God. For Eric and myself it was a strong incentive to pay even more attention to Social Signal Processing (see Van den Herik and Postma, 2009; see also Section 9).

\section{$8 \quad$ Intuition}

The prevailing research question at that time (2005) was encouraged by the possibilities of modern technological resources: Would it really be possible to make visible what you feel, what you know unconsciously? Would cameras and intelligent computer programs play a role in such a project? For example, would it be possible to interpret intuition, to explain it and define it? These were intriguing thoughts. Of course, the main reason was that Jaap still carried the legacy of Adriaan de Groot.

During my Ph.D. research I was ambitious and I wanted to write almost three dissertations. The multidisciplinary field was Computer Chess. The parts were (1) Computer Science and Artificial Intelligence, (2) Heuristics and Thinking Psychology, and (3) Philosophical Foundations upon which all these ideas were based.

For subjects (2) and (3) I had composed an extensive program of research literature and in-depth interviews. For design and development, I refer to Van den Herik (1983). Here intuition is at stake and in this area Donald Michie (1981) put me on the right track. His definition of intuition was a bridging element in the science and psychology convenant (see Subsection 8.5).

I felt that I could do something with this definition, but I had no idea how to give it a meaning. Still, the concepts, the idea and the connections were clear and almost suitable for further elaboration. I will take you on my path, which runs from Rorty, by Poincaré, Euwe and De Groot, to Michie. The main line is formed by Rorty (Subsection 8.1) and Michie (Subsection 8.5). Poincaré, Euwe, and De Groot have been important for my own scientific development.

\subsection{The common definition by Rorty}

In my research on intuition I focussed mainly on problem solving and on adequately formulating concepts for certain situations. According to The Encyclopedia of Philosophy there are four different meanings attributed to

\footnotetext{
${ }^{3}$ Professor Jaap Murre was also involved in the research project as supervisor.
} 
the concept of intuition. As a starting point, I then (and now again) took the common meaning, which comes from Richard Rorty (1967). ${ }^{4}$

Definition 1 (Rorty): "Intuition is unjustified false belief not preceded by inference; in this (the commonest) sense 'an intuition' means 'a hunch'. The existence of hunches is uncontroversial and not of philosophical interest."

Van den Herik (1983) commented on this: "Intuition manifests itself in chess among other things as the designation of the good move without "trying" all of them. The move under inspection should lie within the human window (...). We note that the designation of the good move implies that intuition is a cognitive psychological concept in the sense of 'irrational and yet true', but does not present a way of thinking."

\subsection{Intuition according to Poincaré}

Poincaré (1913, p. 381) notes that not everyone can have some form of intuition. This fits in with De Groot's ideas: intuition is for the happy few, the chess grandmaster. As an illustration, we provide below a relevant quote by Poincaré. ${ }^{5}$

"We know that this feeling, this intuition of mathematical order, that makes us divine hidden harmonies and relations, cannot be possessed by everyone. Some will not have either this delicate feeling so difficult to define, or a strength of memory and attention beyond the ordinary, and then they will be absolutely incapable of understanding higher mathematics. Such are the majority. Others will have the feeling only in a slight degree, but they will be gifted with an uncommon memory and a great power of attention. They will learn by heart the details one after another; they can understand mathematics and sometimes make applications, but they cannot create. Others, finally, will possess in a lesser or greater degree the special intuition referred to, and then not only can they understand mathematics even if their memory is nothing extraordinary, but they may become creators and try to invent with more or less success, according as this intuition is more or less developed in them." [Emphasis added by vdH]

\subsection{Intuition according to Euwe}

More than half a century later, chess grandmaster and former World Champion Max Euwe expressed the same thoughts for chess as did Poincaré for mathematics. Euwe (1964) did so in his inaugural address at the Catholic University of Tilburg.

"The essential element of playing chess at a high level is inspiration. The skill competence of a chess player is based on a multitude of factors, such as directly accessible knowledge, memory, accuracy, ability for combinations, but especially on consolidated experience. De Groot considers the latter as indicative for the distinction between master and non-master. Yet, there are chess masters who (in brief) know everything and see everything and still never will succeed in reaching the highest echelons. It is said that they do not have sufficient imagination. It is thought that these players do not have from time to time a lucid thought, say a hunch." [Emphasis added by vdH]

On June 10, 1980, we discussed this passage on a lucid thought. Can players without having once in a while a lucid thought nevertheless become a strong chess-player? Euwe was succinct:

".... According to my statement then, the answer is no and I still stick to that answer. "

At the time, Van den Herik (1983, p. 473) commented on this passage as follows. "By this statement Euwe emphasises that computer programs in his view, would never play strong, because a computer will never get a hunch and therefore does not play excellent moves."

In brief, Euwe felt that a hunch was not programmable. I assume by this statement "that for Euwe inspiration means: A happy or lucid thought which can give a decisive turn to the game" (Van den Herik, 1983, p. 473).

\footnotetext{
${ }^{4}$ Of course, I am aware that the definitions given by many influential scholars on intuition are not discussed in my approach. The most well-known definitions are by: Kant, Frege, Bergson, Jung, Leibniz, Descartes, Hilbert, and Brouwer.

${ }^{5}$ The emphasis is added by vdH. It was impossible to consult the original French text. Several publications by Poincaré are directly translated from his French manuscript into English.
} 
Adriaan de Groot can be seen as the "grandmaster" of intuition, at least when it comes to chess. He defines the term as follows.

Definition 2 (De Groot): "Intuition is having judgements (or making decisions) in a manner that cannot be made explicit."

In my thesis, this statement is discussed deeply (Van den Herik, 1983, pp. 472-491). Here I confine myself to two points.

(A) De Groot (1965, pp. 308-309) argues that intuition is not irrational, but it still cannot be implemented in program form as a chess player cannot explain intuition itself.

(B) De Groot (1965, pp. 309-310) believes that intuition is not infallible, but it generally ensures a reasonable degree of correctness.

Here, I note that I agree with De Groot that (A) intuition is not irrational and (B) intuition is not infallible (and generates a reasonable degree of correctness). However, I had a dispute with him on the point that intuition cannot be programmed.

\subsection{Intuition according to Michie}

In an in-depth interview with Donald Michie (April 10, 1981, see Van den Herik, 1983, pp. 563-578), a new perspective on intuition was presented. Michie's definition is as follows.

Definition 3 (Michie): "Intuition is simply a name for rule-based behaviour where the rules are not accessible for consciousness."

We note that both the definition by De Groot and that by Michie concur with the common definition by Rorty. However, the definitions by De Groot and Michie themselves are substantially different. Michie does not make a statement on the correctness of intuitive judgement.

\section{$9 \quad$ The place of intuition}

So far we have concentrated on mental intuition with the emphasis on intuition as an element in solving problems. Intuition is, however, a much broader concept. On the site www.encyclo.nl/begrip/intuitie there are twenty definitions of the concept intuition. That is too many for this article. In addition, it leads to new difficulties in the classification of common themes. I therefore start from the following four forms of intuition:

- Mental intuition,

- Physical intuition,

- Emotional intuition, and

- Environmental Intuition.

Below, I will classify (a) spiritual intuition as emotional intuition, and (b) inspiration (see Euwe) as mental intuition. In a footnote in Subsection 8.1 I mentioned already eight researchers who have been dealing with intuition. They usually mention Thinking $(\mathrm{T})$, Sensing $(\mathrm{S})$, Feeling $(\mathrm{F})$ and iNtuiting $(\mathrm{N})$. All researchers find it difficult to grasp the concept of intuition in sufficient detail. It is therefore remarkable that two practical investigators without special training in this direction have proposed a model that has received many followers (mostly human resource people). It is the model MBTI (Myers-Briggs Type Indicator). Mother Myers and daughter Briggs have relied on the theory developed by Carl Gustav Jung (1921). Jung distinguished two directions: (1) Rational: Thinking or Sensing and (2) Irrational: Feeling or Intuiting. Later the direction (3) Introvert or Extrovert was added to the discussion on intuition. Thereafter the fourth direction (4) Judging or Perceiving was added in the MBTI model. It is generally known that there is neither a scientific basis for Jung's work nor for the work by Myers and Briggs (see, e.g., nl.wikipedia.org/wiki/Myers-Briggs_Type_Indicator). In addition, I would like to remark that the work by Myers-Briggs is not consistent with the evidence-based Big Five personality dimensions (see Wiggings, 1996). Promotus Giel van Lankveld (2013) focussed on the Big Five, but did not address the differences with Myers-Briggs. A few interesting but otherwise differently coloured ideas about intuition were echoed by Henk Barendregt (2015). In his farewell speech he examined the 
keys to two intimate feelings based on Mathesis and Mysticism. He did so by adding the personal and nonpersonal. Moreover, Mark Dechesne pointed my attention to John R. Anderson (1982) Acquisition of Cognitive Skill. The article provides on explanation for three stages of acquisition of cognitive skill, viz. the cognitive stage, the associative stage, and the autonomous stage. There is no explicit relation with the concept intuition, but it could be argued that the three stages are helpful to define mental intuition. Finally, Frits Berends referred me to Feynman's (1965), Nobel lecture in which the Nobel laureate made some thought provoking remarks on the benefits of using "the intuition method". The relevant citation is as follows.

“(...) I did know from experience, from fooling around, that everything was, in fact, equivalent to the regular electrodynamics and had partial proofs of many pieces, although, I never really sat down, like Euclid did for the geometers of Greece, and made sure that you could get it all from a single simple set of axioms. As a result, the work was criticized, I don't know whether favorably or unfavorably, and the "method" was called the "intuitive method". For those who do not realize it, however, I should like to emphasize that there is a lot of work involved in using this intuitive method successfully. Because no simple clear proof of the formula or idea presents itself, it is necessary to do an unusually great amount of checking and rechecking for consistency and correctness in terms of what is known, by comparing to other analogous examples, limiting cases, etc. In the face of the lack of direct mathematical demonstration, one must be careful and thorough to make sure of the point, and one should make a perpetual attempt to demonstrate as much of the formula as possible. Nevertheless, a very great deal more truth can become known than can be proven.” [Emphasis added by vdH]

In this article I have endeavoured to find a more "down to earth" approach. Through my sparring partner Hans Konstapel $^{6}$, I arrived at the theory by Will McWhinney (1984).

\subsection{The Model by McWhinney}

In his fascinating publication Grammars of Engagement Will McWhinney covers several different perspectives that we can have on the world. His constructions consist mainly of four elements, which pairwise have a relationship. To give you an idea I reproduce in Table 1, A Variety of Models That Use Four Similar Modes (in Grammars of Engagement, Figure 3.4).

THE FOUR MODES

\begin{tabular}{|c|c|c|c|c|c|}
\hline \multirow{2}{*}{$\begin{array}{l}\text { SOURCE } \\
\text { FOUR } \\
\text { REALITIES }\end{array}$} & \multicolumn{2}{|c|}{ DETERMINED } & \multicolumn{2}{|c|}{ VOLUNTARISTIC } & \multirow{2}{*}{$\begin{array}{l}\text { REFERENCES \& COMMENTS } \\
\text { McWhinney (1984). }\end{array}$} \\
\hline & Unitary & Sensory & Social & Mythic & \\
\hline BUDDHIST & Samjña & Rupa & Vedana & Samskara & Conze (1951). \\
\hline Plato & Reason & $\begin{array}{l}\text { Under- } \\
\text { standing }\end{array}$ & $\begin{array}{l}\text { Opinion } \\
\text { (faith) }\end{array}$ & $\begin{array}{l}\text { Perception of } \\
\text { Shadows }\end{array}$ & $\begin{array}{l}\text { Jowett's terms from The Republic and } \\
\text { Gilbert Ryle (1967) }\end{array}$ \\
\hline GosPeLs & $\begin{array}{l}\text { Matthew } \\
\text { (Lion) }\end{array}$ & $\begin{array}{l}\text { Mark } \\
(\mathrm{Ox})\end{array}$ & $\begin{array}{l}\text { Luke } \\
\text { (Man) }\end{array}$ & $\underset{\text { (Eagle) }}{\text { John }}$ & $\begin{array}{l}\text { The parallels were observed and analyzed } \\
\text { by John Lai (1996). The metaphors are } \\
\text { from Revelation, } 4: 7\end{array}$ \\
\hline $\begin{array}{l}\text { LAKOTA } \\
\text { INDIAN }\end{array}$ & $\begin{array}{l}\text { North } \\
\text { (Buffalo) }\end{array}$ & $\begin{array}{l}\text { South } \\
\text { (Mouse) }\end{array}$ & $\begin{array}{c}\text { West } \\
\text { (Bear) }\end{array}$ & $\begin{array}{c}\text { East } \\
\text { (Eagle) }\end{array}$ & $\begin{array}{l}\text { Storm (1972) writing from a Plains Indian } \\
\text { worldview. }\end{array}$ \\
\hline JUNG & Thinking & Sensing & Feeling & Intuiting & Jung's Personality Types, (1920) \\
\hline LESHAN & Clairvoyant & Sensory & Transpsychic & Mythic & $\begin{array}{l}\text { Lawrence LeShan (1976). } \\
\text { Descriptions of exceptional people. }\end{array}$ \\
\hline HERMANN & $\begin{array}{l}\text { Left } \\
\text { Cerebral }\end{array}$ & $\begin{array}{l}\text { Left } \\
\text { Limbic }\end{array}$ & $\begin{array}{l}\text { Right } \\
\text { Limbic }\end{array}$ & $\begin{array}{l}\text { Right } \\
\text { Cerebral }\end{array}$ & Ned Hermann (1989). \\
\hline LATOUR & Being & $\begin{array}{l}\text { External } \\
\text { Reality }\end{array}$ & $\begin{array}{l}\text { Social } \\
\text { Bond }\end{array}$ & $\begin{array}{l}\text { Signification } \\
\text { and Meaning }\end{array}$ & Bruno Latour (1991). \\
\hline
\end{tabular}

Table 1: Nine Models with Four Similar Modes.

\footnotetext{
${ }^{6}$ For many years Hans Konstapel and I were advising Leen Zevenbergen and later on Berry Veldhoen (Bolesian). Konstapel then was leading the Department of Innovation of Automatisation at ABN AMRO.
} 
The ideas by McWhinney published in Grammars of Engagement bring us back to Jung (see Table 1). After all, Jung is the only contributor who called intuition by the name Intuiting in Table 1 . Yet, we see that in this column there are also other ideas, such as Right Cerebral (Hermann, 1989) and Signification and Meaning (Latour, 1991). These ideas led intuition away from the stamp "irrational" which by some (not De Groot and Euwe) is now and then given to intuition.

To stimulate the mind, I propose below a simple model of possible connections. The "mind" model consists of four components, namely $\mathrm{T}$ (Thinking), S (Sensing), F (Feeling) and $\mathrm{N}$ (iNtuiting). As so often, the essence does not lie in modelling the components per se, but it lies in the connections and their substantiations. For now I only discuss four mutual connections, namely $\mathrm{T} \leftrightarrow \mathrm{S}, \mathrm{S} \leftrightarrow \mathrm{F}, \mathrm{F} \leftrightarrow \mathrm{N}, \mathrm{N} \leftrightarrow \mathrm{T}$. In the literature you will find many descriptions and explanations of these links. In Figure 1, each connection is personalised by a person earlier mentioned in this article. I leave the interpretation of the names assigned to the connections to the readership.

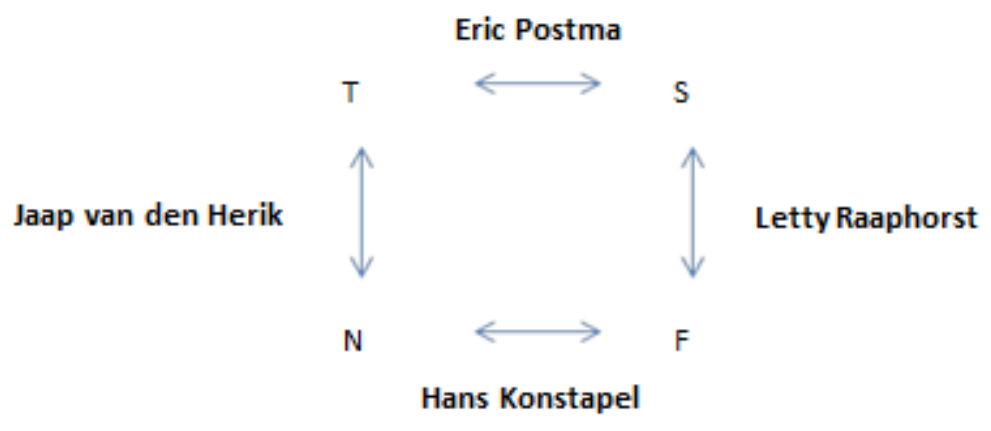

Figure 1: An Instantiation of the Four Modes.

$\mathrm{N}$ (Intuition) has also some relation with imagination. One of the most inspirational figures in the area of imagination is Leibniz. As is well known, his approach to mathematics and physics was rather different from that of Newton. Leibniz was a Renaissance man who was driven by the question: how can we imagine what is interesting? As Konstapel told me: "In the Renaissance period researchers can be best characterised as persons who looked through a very narrow opening ("peephole") in order to understand the genesis of the 'perspective'." This is probably the way we nowadays look at a former generation of researchers dealing with intuition. For the current researchers, the prevailing question is whether there exists a design for programming intuition.

The research in the area of Pattern Recognition, that started with Rens Kortmann, Michel van Dartel, Joyca Lacroix, Niek Bergboer, and Fred Hamburg (see Section 7) was continued by Guido de Croon. He examined the straightforward question: How do adaptive active vision models handle challenging visual tasks? What he did not know (and also not his supervisors) was that his research was well suited for controlling drones. In this article, however, I consider his results only as a step towards the implementation of intuition.

\subsection{Adaptive Active Vision}

Around 1980, the area of vision investigation was dominated by passive Computer Vision Systems (cf. Marr, 1982). Some ten years later, the idea emerged that active foveal vision systems could have major benefits. The reason is that such a system would be able to process a foveal portion of the visual picture with high resolution (cf. Ballard, 1991). Two immediate advantages were: (1) the simplification of relevant tasks by the introduction of actions, and (2) the reduction of computational operations, because only a portion had to be treated.

Soon evolutionary algorithms were introduced to provide robots with an action strategy for performing their duties. This resulted in several optimisation algorithms; adapting a strategy to the tasks to be carried out played an important role. It even became a research domain of its own right, viz. that of Coevolution of Active Vision and Feature Selection (cf. Floreano et al., 2004). When De Croon began his research he saw three open issues, namely (1) it was uncertain whether adaptive active vision models could successfully be applied to difficult 
tasks in computer vision, (2) until then the researchers did not understand exactly how adaptive active vision worked, and (3) it was unclear what effect adaptive active vision would have in a control task? The adaptive approach led to the surprising insight that virtual eye movements can serve not only to gather information, but also (a) to avoid disturbing visual observations, and (b) to use the environment as external memory to maximize the job-specific information in the observations.

\subsection{Dimension Reduction}

The study by De Croon was followed by excellent results achieved by Laurens van der Maaten (2009) on Feature Extraction from Visual Data. His work was awarded with the judicium cum laude. ${ }^{7}$ The thesis is a technical dissertation on dimension reduction. Laurens has worked as part of his thesis with Geoffrey Hinton, who was then a professor at the University of Toronto. Together with Hinton, Laurens has developed a dimension reduction method which is currently used worldwide. The unpublished internal survey of dimension reduction methods is a frequently quoted output result of the three of us (van der Maaten, Postma and van den Herik, 2009, 361 citations).

The scientific triad (active vision - dimension reduction - deep learning) became transparent for Eric and me around 1995. At that time neural investigations by Geoffrey Hinton and his colleague Yan LeCun, inspired us to investigate automatic pattern recognition. Patrick Hudson initiated the first contact and Laurens made the connection to the point by realising what Eric and myself had developed in an elementary way. Now, twenty years later, Hinton and LeCun form the core of the deep learning revolution (LeCun, Bengio, and Hinton, 2015). Hinton is currently working part-time for Google and LeCun is Director of the AI research laboratory of Facebook. Laurens is one of his assistants. With deep learning many successes are being achieved in the field of pattern recognition, but there are not yet applications in the direction of intuition. That will be done by the successors of Ruud Mattheij (see below) and in the area of Go by GoogleMind.

\subsection{Analysis of Paintings}

The step to intuition goes via pattern recognition. This was the theme of the thesis by Igor Berezhnoy (2009); it was entitled Digital Analysis of Paintings. Berezhnoy's third research question is: Are there any visual features that serve as fingerprints of the author and may reveal his identity independently of his style or the painted subject? This comes close to recognising intuitive expressions in art. However, it is still different from creating intuitive expressions. Nevertheless, the key to progress is in this study. The idea is that after recognition the researcher may save results for future use. The stored results can then be used to generate intuitive expressions (say, create intuitive facial or behavioural expressions).

\subsection{Through the Looking Glass}

In the specific domain of pattern recognition our cooperation with the Eindhoven University of Technology (TU/e) played an important role. Around 2007 the group led by Cees Midden (TU/e) began to develop new techniques for autonomous systems to convince ordinary people that they (1) should use less energy than they are using and (2) should store unused energy. It was an ambitious project in which technological and psychological knowledge were needed to create a successful interaction between people (users) and agents (computer programs that give wise guidance, the agents are also known as embodied agents). It was a challenging project, where it soon became clear that the main obstacle was in personalised feedback that was socially acceptable. Thus in 2010 Midden \& Ham (TU/e) and Postma \& Van den Herik (Tilburg University) composed and wrote a new project proposal entitled Persuasive Agents in which feedback was central, i.e., to understand what drives the other companion, in other words, the issue is understanding non-verbal communication. The project was awarded in late 2010.

In 2011 Ruud Mattheij was appointed as Ph.D. student to conduct the above challenging research project. The entire group of investigations consisted of researchers from Informatics (Tilburg) ${ }^{8}$ and Psychology (Eindhoven) ${ }^{9}$, as well as practitioners from Smart Homes Foundation ${ }^{10}$. Below I provide a description of the research mainly on the basis of images with associated text.

\footnotetext{
${ }^{7}$ Of the 71 theses I delivered two promoti with this judicium; the other thesis was by Antal van den Bosch (1997).

${ }^{8} \mathrm{https} / / /$ www.tilburguniversity.edu/research/institutes-and-research-groups/ticc

${ }^{9}$ http://www.tue.nl/universiteit/faculteiten/industrial-engineering-innovation-

sciences/onderzoek/onderzoeksgroepen/human-technology-interaction
} 


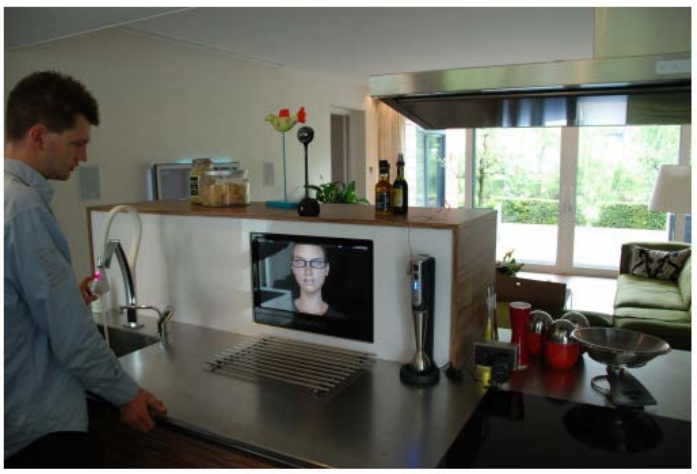

Figure 2: Interaction between man and embodied agent.
Figure $2^{11}$ shows how an embodied agent tries to convince a "member of the household" that he ${ }^{12}$ would have to use less water. Personalised feedback asks for subtle facial expressions (sad or angry, if too much water is used). But more importantly for the embodied agent is recognising (a) the facial expressions of the member of the household, and (b) preferably also his intuitive feelings. In the following, I will use Eric Postma (in text and pictures) as an example of a household member. The problem statement of Mattheij's Ph.D. thesis reads: To what extent is it possible to detect body parts and behaviour when using in-depth information?

In Figure $3^{13}$, the work plan of the problem statement is described as follows:

(A) analysing the output of the sensor array,

(B) formulating personified feedback,

(C) storing Eric's behaviour (social cues and behaviours), and

(D) filling of the precise roles of the sensor array.

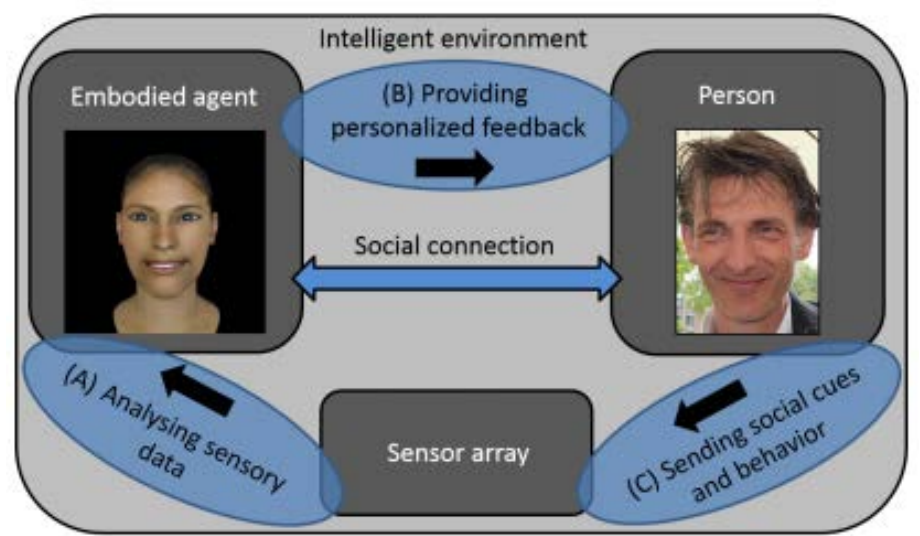

Figure 3: Four research tasks.

Mattheij first studied The Microsoft Kinect device (see, e.g., Smisek et al., 2013). The Kinect device generates depth images by (1) reducing the spatial area with an infrared laser and (2) triangulating of the corresponding depth with the infrared sensor results. The depth images have a resolution of 640x480 pixels. Shotton et al. (2013a,b; 2011) used the Kinect for recording the depth-orientation of the body parts by capturing the individual pixel location in single-depth images. A detailed description is in Shotton et al. (2013a,b; 2011). An insightful summary is in Mattheij (2016). The essence is that Shotton et al. emphasise the pixel-based comparisons.

Mattheij's idea is to use proper sensor images for region-based comparison and not for pixel-based comparison. In his thesis he offers arguments and demonstrates the strength of RC (Region-based Components) compared to PC (Pixel-based Components) convincingly in three experiments (see Mattheij, 2016).

The RC-characteristics are highly relevant to the development of embodied agents which are intended to capture accurately the natural interactions with humans, and then to use the results in their conversation.

\footnotetext{
${ }^{10}$ http://www.smart-homes.nl

${ }^{11}$ Adopted from Mattheij (2016).

${ }^{12}$ For brevity, I use 'he' and 'his' whenever 'he or she' and 'his or her' are meant.

${ }^{13}$ Adopted from mattheij (2016).
} 
To accomplish these two tasks the detectors should be trained (by the region-based comparison detector) to interpret the deep data that contain spontaneous human behaviour and unconscious intuitive behaviour, to interpret them appropriately and then store the behaviours. So far, however, no databases are available in the public domain that contain thorough annotated depth images of people making spontaneous gestures, let alone of people exhibiting intuitive behaviours.

For this purpose Ruud Mattheij has developed an annotated database called STAGE. There, the visual representations with the depth data of human gestures and facial expressions are saved. Mattheij subsequently examined to what extent people's verbal and non-verbal expressions appearing in an embodied agent were mimicked by the embodied agents. His results are based on an embodied agent with a human appearance (see Figure 2) communicating verbally and nonverbally.

The procedure is partitioned into three types of registration: (1) the changes in the pitch of the voice, (2) the changes in the speed of speaking, and (3) the difference in facial expressions that caused the changes. It appears that small localised changes of behaviour in the visual and auditory domain lead to (a) significant changes in human facial expressions and (b) detectable changes in the vocal behaviour. Often the intuitive behaviour changes. The results therefore imply that people react to embodied agents (with whom they are familiar) as ordinary interlocutors. Based on these observations Mattheij concludes that people can have a social relationship with embodied agents who are similar to human beings.

In Figure $4^{14}$ we see four blocks in the sensor array, with results from Mattheij’s research (research task D). They are:

(1) a detector which can compare the regions (instead of pixels) with each other,

(2) a sensor that can observe rather deep layers,

(3) a detector that can search the database (STAGE), and

(4) a set of features which are region-based.

The detector compares these regions with each other and uses the sensor which can detect images at deep layers by looking through a very narrow opening ("peephole”). In this way the intuitive perspective as attributed to Leibniz (see Subsection 9.2) becomes a reality in the form of seeing "through the looking glass".

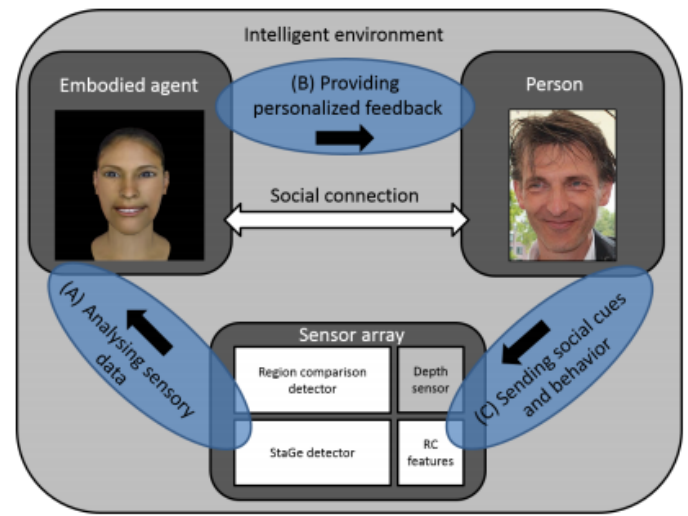

Figure 4: Four tangible results of research task D.

\subsection{My Claim}

For recognising paintings (see, e.g., Berezhnoy, 2009) we have seen that success is based on recognition of (1) the brush stroke, (2) the composition, and (3) the colour combination. Minimal differences can lead to different answers. The storage of these features resulted in a database which basically contains all the characteristics of a painter (e.g., Van Gogh). From these characteristics a suitable program can then compose a "new" Van Gogh. The new painting is a "perfect" Van Gogh. Possibly only seasoned experts may see that it is not a true Van Gogh, because Van Gogh was a human being who is gifted by nature to make small mistakes towards his own style; a computer program does not.

\footnotetext{
${ }^{14}$ Adopted from Mattheij (2016).
} 
What is true in painting has already taken place in the world of music composers. There are compositions in Bach's and Mozart's style that are composed by a computer program (see Cope, 2000, 2008). To streamline the procedure Cope has developed four tools: Liquid Notes, Quartet Generator, Easy Music Composer and Maestro Genesis. To obtain a clear picture of what is going on in the world of music composition by computer, I refer the reader to engineersonline.nl (2015). The title alone will make you realise that the developments are changing fast, The computer as a composer: the high-tech answer to Mozart (March 17).

All in all, it is clear that AI developments in painting and music composition put us on the right track. Moreover, Louwerse et al. (2012) have already shown that matching of behaviours in multimodal communication occurs in a synchronized way. If we can also save the human behaviours (as in STAGE) and if we can register intuitive decisions and indicate them, then it should be possible to obtain the intuitive considerations hidden in all available data. Consequently, a programmer may make those identified intuitions accessible in computer program formulations that fit other components in the overall program. It is similar to genetic engineering, where researchers are also involved in identifying genes that cause serious afflictions.

To summarise, I am convinced that we can take elements from registered intuitive behaviours, which we can then implement as program blocks in the AI programs of the future. It means nothing more and nothing less than that intuition can be programmed.

\section{Conclusion: Science Lives by Contradiction}

I started the article by a tribute to my mentor Adriaan de Groot. He has shown me the right path. However, his erudite words asked for contradiction.

Contradiction and setback are gifts of the rational thought processes. How can I deal with a difference of opinion? How do I fix this? Contradiction and setback lead to values that are formative for your entire life. My conclusion is therefore that the best results come from studies where a doctoral student and the supervisor disagree on a relevant part of the research. In my inaugural speech in Maastricht (Van den Herik, 1988), I thanked my supervisor Joop Doorman for his opposition to many of my ideas with the words: Du choc des opinions jaillit la verité!

I hope that I am still given to supervise many future Ph.D. students.

\section{Words of Appreciation}

At the end of this valedictory address as Editor-in-Chief of the ICGA Journal, I consider it a real privilege to pronounce words of gratitude. The list could be long but I will confine myself to the main characters in my ICCA/ICGA Journal life. First of all, Ben Mittman who invited me to be his successor as Editor of the ICCA Newsletter, which I gratefully accepted. Subsequently, Ken Thompson, Jonathan Schaeffer, Tony Marsland, and David Levy continuously supported me to bring the Journal into the ranks of a worldwide recognised Journal that was regarded as a highly appreciated quarterly publication on Chess and Games. From them I single out Jonathan Schaeffer for all additional help and friendship ranging from 1983 to 2016.

Then, I thank my very special Ph.D. students Hiroyuki Iida (to be considered as such), Don Beal, Brian Sheppard, and David Levy (again). Of course, my thanks also goes to a long list of contributing referees, and members of the Editorial Board. Thank you all for the long-time cooperation. Here, two exceptions are to be honoured. Although they are Dutch, they always acted as truly international computer-chess aficionados. The first great exceptional person is Bob Herschberg. He taught me to be an Editor-in-Chief. Thank you Bob, for all your lessons. Then, I would like to thank Dap Hartmann. Over thirty years his reviews were welcomed, feared and appreciated. He did a great job. Many thanks to Dap.

Finally, I would like to thank four ladies who made it possible that I could address our readership so well. They served me over the years excellently, because they tried to understand my intuition. I am grateful to Joke Pesch (Delft University of Technology 1983-1987), Hadewich Bollen (Maastricht University 1987-1990), Tons van den Bosch (Maastricht University 1990-1997), Joke Hellemons (Maastricht University, Tilburg University, Leiden University 1994-2016). 


\section{References}

Anderson, J.R. (1982). Acquisition of Cognitive Skill, Psychological Review, Vol. 89, No. 4, pp. 369-406.

Ballard, D.H. (1991). Animate Vision. Artificial Intelligence, Vol. 48, No. 1, pp. 57-86.

Barendregt, H. (2015). Sleutels tot twee intimiteiten: Mathesis en Mystiek, Valedictory Address, Radboud University Nijmegen, 1 October.

Berezhnoy, I. (2009). Digital Analysis of Paintings. Ph.D. Thesis, Tilburg University, 7 December.

Bergboer, N. (2007). Class and Object Detection in Natural Images. Ph.D. Thesis, Maastricht University, 10 October.

Conze, E. (1951). Buddhism. Philosophical Library, Incorporated, 1 December.

Cope, D. (2000). The Algoritmic Composer. A-R Editions, Madison, Wi.

Cope, D. (2008). Hidden Structure: Music Analysis Using Computers. A-R Editions, Madison, Wi.

Croon, G.C.H.E. de (2008). Adaptive Active Vision. Ph.D. Thesis, Maastricht University, 26 June.

Dartel, M. van (2005). Situated Representation. Ph.D. Thesis, Maastricht University, 1 December.

Engineersonline.nl (2015). De computer als componist: het hightech antwoord op Mozart. (17 March). Engineersonline.nl/nieuws/id24972_de_computer_als_componist_het_hightech_antwoord_op_mozart_video.html

Euwe, M. (1963). Computer en Schaakspel. Contract Semec 013-61-4 CETH, Stichting Studiecentrum voor Administratieve Automatisering, Amsterdam.

Euwe, M. (1964). Kunnen Computers Denken? Inaugural Address, Katholieke Hogeschool Tilburg. P. Noordhoff N.V., Groningen.

Feynman, R.P. (1965). The Development of the Space-Time View of Quantum Electrodynamics, Nobel lecture, December 1.

Floreano, D., Kato, T., Marocco, D., and Sanser, E. (2004). Coevolution of Active Vision and Feature Selection. Biological Cybernetics, Vol. 90, pp. 218-228.

Groot, A.D. de (1946). Het Denken van den Schaker, een Experimenteel-psychologische Studie. Proefschrift, Universiteit van Amsterdam; N.V. Noord-Hollandsche Uitgevers Maatschappij, Amsterdam.

Groot, A.D. de (1965). Thought and Choice in Chess (ed. G.W. Baylor) (translation with additions from De Groot (1946)). Second edition 1978. Mouton Publishers, The Hague-Paris, New York.

Groot, A.D. de (1983). Over Schakersintuïtie of Computers als wereldkampioen, de blinde vlek van Van den Herik. Intermediair, No. 28, p. 27-29.

Groot, A.D. de (1997). Intuïtie is onmisbaar voor schakers, NRC Handelsblad, 27 May.

Hamburg, F. (2005). Een Computermodel voor het Ondersteunen van Euthanasiebeslissingen. Ph.D. Thesis, Leiden University, 24 November.

Herik, H.J. van den (1983). Computerschaak, Schaakwereld en Kunstmatige Intelligentie. Ph.D. Thesis, Delft University of Technology, 21 June.

Herik, H.J. van den (1988). Informatica en het Menselijk Blikveld. Inaugural Address, Maastricht University, 21 October.

Herik, H.J. van den and Postma, E.O. (2009). Geloof in Computers. Inaugural Address, Tilburg University, 27 March.

Hermann, N. (1989). The Creative Brain. Brain Books, 1 September.

Jung, C.G. (1920). Personality Types. http://www.personalityapps.com/Personality_Types/Theory.html Jung, C.G. (1921). Psychological Types, Collected Works, Vol. 6. Routledge, London. 
Kortman, R. (2003). The Resolution of Visually Guided Behaviour. Ph.D. Thesis, Maastricht University, 4 July.

Lacroix, J. (2007). NiM: A Situated Computational Memory Model. Ph.D. Thesis, Maastricht University, 20 September.

Lai, J. (1996). Worldviews in Collision: Understanding Denominational Conflict. Redlands.academia.edu.

Lankveld, G. (2013). Quantifying Individual Player Differences. Ph.D. Thesis, Tilburg University, 27 February.

Latour, B. (1991). Essai d’anthropologie symétrique. La Découverte.

LeCun, Y., Bengio, Y., and Hinton, G. (2015). Deep learning. Nature, Vol. 521, pp. 436-444.

LeShan, L. (1976). Alternate Realities. The Search for the Full Human Being. Lippincott.

Louwerse, M.M., Dale, R., Bard, E.U., and Jeuniaux, P. (2012). Behavior Matching in Multimodal Communication is Synchronized. Cognitive Science, Vol. 36, No. 8, pp. 1404-1426.

Maaten, L.J.P. van der (2009). Feature Extraction from Visual Data. Ph.D. Thesis (cum laude), Tilburg University, 23 June.

Maaten, L.J.P. van der, Postma, E.O., and van den Herik, H.J. van den (2009) Dimensionality Reduction: A Comparative Review. TiCC Technical Report 2009-005.

Marr (1982). Vision: A Computational Investigation into the Human Representation and Processing of Visual Information. Freeman, New York, N.Y.

Mattheij, R. (2016). The Eyes Have It. Ph.D. Thesis, Tilburg University (under assessment).

McWhinney, W. (1984). Grammars of Engagement. Published as report, Fielding Graduate University, Santa Barbara, Ca.

Michie, D. (1981). Interview with Donald Michie (10 april) in: Van den Herik (1983), Appendix E, pp. 563-578.

Poincaré, H. (1913). The foundations of science. Science Press, New York. Mathematical Creation, reprinted in 'The World of Mathematics’ (ed. J.R. Newman), Vol. 4, part XVIII, pp. 2041-2050, George Allen and Unwin Ltd., London.

Postma, E.O. (1994). SCAN: A Neural Model of Covert Attention. Ph.D. Thesis. Maastricht University, 22 September.

Rorty, R. (1967). Intuition. The Encylopedia of Philosophy (ed. In chief: P. Edwards), Vol. 4, pp. 204-121, The Macmillan Company \& The Free Press, New York; Collier-Macmillan Limited, London.

Ryle, G. (1949). The concept of mind. Hutchinson \& Co. Ltd., London. J.O. Urmson (1967) citeert Ryle in zijn Routledge Encyclopaedia lemma voor Ryle.

Shotton, J., Fitzgibbon, A., Cook, M., Sharp, T., Finocchio, M., Moore, R., and Blake, A. (2011). Real-time human pose recognition in parts from single depth images. In Proceedings of the IEEE conference on computer vision and pattern recognition, pp. 1297-1304. Washington, DC: IEEE Computer Society.

Shotton, J., Fitzgibbon, A., Cook, M., Sharp, T., Finocchio, M., Moore, R., and Blake, A. (2013a). Real-time human pose recognition in parts from single depth images. In R. Cipolla, S. Battiato, \& G. M. Farinella (Eds.), Machine learning for computer vision, Vol. 411, pp. 119-135. Springer, Heidelberg.

Shotton, J., Girshick, R., Fitzgibbon, A., Sharp, T., Cook, M., Finocchio, M., and Blake, A. (2013b). Efficient human pose estimation from single depth images. IEEE Transactions on Pattern Analysis and Machine Intelligence, Vol. 35, No. 12, pp. 2821-2840.

Smisek, J., Jancosek, M., and Pajdla, T. (2013). 3d with Kinect. In A. Fossati, J. Gall, H. Grabner, X. Ren, \& K. Konolige (Eds.), Consumer depth cameras for computer vision (pp. 3-25). Springer, London.

Storm, Hyemeyohsts (1972). Seven Arrows. Harper \& Row, New York.

Wiggings, J.S. (1996). The five-factor model of personality: Theoretical perspectives. The Guilford Press, New York, London. 